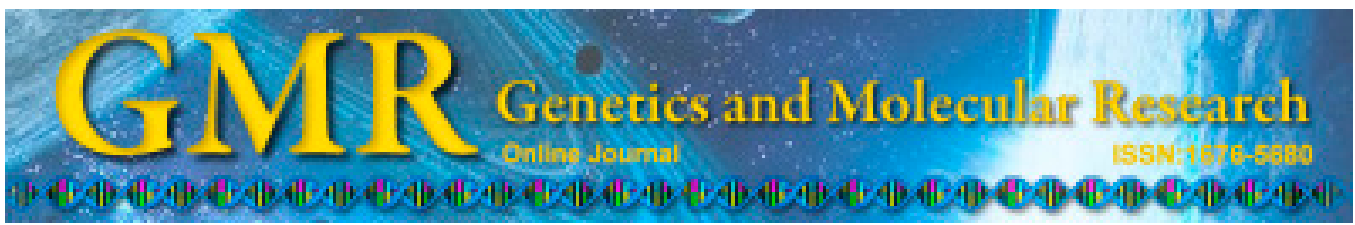

\title{
Molecular cloning, characterization and expression analysis of a Doublesex gene from Daphnia carinata (Crustacea: Cladocera) during different reproductive stages
}

\author{
M.Q. Zhang ${ }^{1 *}$, C.A. Ma ${ }^{1 *}$, W.W. Lv ${ }^{1}$, Y.H. Huang ${ }^{1}$, D.L. Wang ${ }^{2}$ and \\ Y.L. Zhao ${ }^{1}$ \\ ${ }^{1}$ School of Life Science, East China Normal University, Shanghai, China \\ ${ }^{2}$ School of Marine Sciences, Ningbo University, Ningbo, China \\ *These authors contributed equally to this study. \\ Corresponding author: Y.L. Zhao \\ E-mail: zhaoyunlong_ecnu@163.com
}

Genet. Mol. Res. 14 (2): 5930-5842 (2015)

Received August 14, 2014

Accepted March 6, 2015

Published June 1, 2015

DOI http://dx.doi.org/10.4238/2015.June.1.10

\begin{abstract}
To better understand the reproductive transformation mechanism of Daphnia carinata, a Doublesex (Dsx) gene was cloned based on rapid amplification of cDNA ends (RACE), and was designated DapcaDsx2. Next, we compared similarities and assumed homology based on deduced amino acid sequences. It showed 97.52, 87.94, and $85.11 \%$ identity to orthologous genes in D. magna, D. pulex, and $D$. galeata respectively. Phylogenetic analysis revealed that DapcaDsx 2 clustered in the same class, and was evolutionarily more distant to sequences from other species. qRT-PCR showed that DapcaDsx2 was most abundantly expressed during sexual reproduction $(\mathrm{P}<0.05)$. Using digoxigenin-labeled RNA probes, we studied DapcaDsx2 expression in parthenogenetic and sexual females by whole-mount in situ hybridization. The results revealed that DapcaDsx 2 was mainly
\end{abstract}


expressed in the second antennae and several sites of the ventral carapace, whereas higher expression levels were found in sexual than in parthenogenetic females. This suggests that the DapcaDsx 2 gene is involved in switching modes of reproduction and in sexual differentiation.

Key words: Daphnia carinata; DapcaDsx2 gene; Expression analysis; Whole-mount in situ hybridization; Reproductive transformation

\section{INTRODUCTION}

Sex determination is a fundamental biological process, mainly referring to male and female undifferentiated gonads developing into testes or ovaries. In vertebrates, sex determination mechanisms can be divided into genetic sex determination (GSD) and environmental sex determination (ESD) (Marshall-Graves, 2008; Crews and Bull, 2009). Due to their more primitive evolutionary status, sex chromosomes in apparent inferior animals do not differentiate or, in the absence of sex chromosomes, sex determination for both GSD and ESD is more complex (Wallace and Wallace, 2000; Matsuda et al., 2002; Valenzuda et al., 2006; Yoshimoto et al., 2008).

Daphnia is considered a model organism for life science research because of its unique reproductive transformation, providing a relatively simple system for the investigation of the relationship between GSD and ESD. Daphnia has two special reproductive modes-parthenogenesis and sexual reproduction. If external conditions are suitable, reproduction occurs generally through parthenogenesis. It has a sexual dimorphism. Parthenogenic Daphnia produce eggs that develop into offspring without fertilization (Zhang, 2005). However, under adverse environmental conditions, such as temperature changes, starvation, or overpopulation, Daphnia produce males and bisexual females, and reproduction switches from an asexual to a sexual mode. In sexual reproduction, the formation of resting eggs, which are fertilized and coated by ephippiums, helps them to survive adverse conditions (Jiang and Du, 1979). Several studies have analyzed cladoceran population growth, reproduction, development, and environmental conditions (Rao et al., 2002; Li and Zhang, 2006). However, most of the studies focused on temperature, food, population density, metabolites, and other external environmental factors (Martinez et al., 1994; Alekseev and Lampert, 2001; Pedrozo and Bohrer, 2003). Previously, Kato et al. (2011) identified two Doublesex (Dsx) genes (DapmaDsx1 and DapmaDsx2) from a freshwater branchiopod crustacean, Daphnia magna. And Toyota et al. (2013) identified homologs of both Dsx genes from Daphnia pulex, Daphnia galeata, and Ceriodaphnia dubia.

$D s x$ is a sex-determining gene initially discovered in Drosophila, and later researched in Bombyx mori (Lalli et al., 2003). Dsx is required to produce any sex phenotype, and its mutation can change the sex phenotype, leading to XX embryos developing into adult males, or XY embryos into adult females. In Drosophila, the function of Dsx results in different phenotypes in males and females, and therefore has opposing regulatory functions (Shearman and Frommer, 1998). According to the different stages of pre-mRNA, Dsx is spliced sex-specifically, which affect its expression levels, and is transcribed into sex-specific mRNA isoform (Shimada and Ohbayashi, 2000).

Daphnia carinata is an aquatic arthropod (Crustacea: Cladocera: Daphniidae) present in fresh water. In the literature, there are fewer studies about $D$. carinata than D. magna, $D$. pulex, and others. Therefore, we aim to identify new details about this species, provide 
supplementary research on the $D s x$ gene, and explore the molecular mechanisms of reproductive switching and environmental sex determination in $D$. carinata. In our study, a full-length cDNA sequence of the Dsx gene was amplified from D. carinata and was named DapcaDsx 2 according to the NCBI database homology analysis. On this basis, a comparative analysis of individuals at different reproductive stages was performed to study the relative and spatial expression of this gene by whole-mount in situ hybridization, intending to explore the expression pattern and functions of DapcaDsx2. In this study, the role of DapcaDs 2 2 in the reproductive transformation of $D$. carinata was investigated, thereby providing a theoretical basis for the reproductive transformation mode and developmental origin of cladocerans and for regulation of animal reproduction development.

\section{MATERIAL AND METHODS}

\section{Sample preparation and reagents}

D. carinata were obtained from the Minhang campus channel of the East China Normal University. A healthy laboratory sample of $D$. carinata was incubated at $25^{\circ} \mathrm{C}$, under a 14-h light/10-h dark photoperiod and fed cladoceran nutrient solution (1.5 g manure, $2 \mathrm{~g}$ vegetables, $20 \mathrm{~g}$ fertile soil in $1 \mathrm{~L}$ boiled, filtered water) for 2-3 weeks. Different sexes of $D$. carinata in response to environmental cues were collected through artificial cultivation. We selected and confirmed differential development of offspring following observations using a Leica DM500 microscope (Leica, Germany). Of these, prophase sexual females and sexual females produce resting eggs, but the ephippia of prophase sexual females is white, while the other is black (Zhang, 2005). Some individuals were immediately frozen in liquid nitrogen and stored at $-80^{\circ} \mathrm{C}$ for RNA extraction. Others were preserved overnight in $4 \%$ paraformaldehyde (PFA) at $4{ }^{\circ} \mathrm{C}$, followed by the removal of PFA and replacement with $100 \%$ methanol, and storage at $-20^{\circ} \mathrm{C}$ for use in whole in situ hybridization experiments.

Total RNA was extracted using an RNA extraction kit (Axygen, USA). A Premix Ex $T_{a q}{ }^{\mathrm{TM}}$ Hot Start version kit (TaKaRa, Japan) was used for qRT-PCR. Reverse transcriptase, Taq polymerase, and other reagents were purchased from TaKaRa. Rapid amplification of cDNA ends (RACE-PCR) was performed using a SMARTer ${ }^{\mathrm{TM}}$ RACE cDNA amplification kit (Clontech, USA). The T7 and SP6 RNA polymerases were purchased from Promega, USA. RNA from torula yeast (Candida utilis) was purchased from Sigma, USA. DIG RNA labeling mixture, blocking reagent, anti-Digoxigenin-AP Fab fragments, and NBT/BCIP were purchased from Roche, USA. PCR primers were synthesized by Sangon, China, and PCR products were sequenced by Majorbio, China.

\section{Primer design}

The gene sequences of $D s x$ homologs were downloaded from the NCBI database. The sequences of D. pulex (GenBank accession No. AB693159.1), D. magna (GenBank accession No. AB569298.1), D. galeata (GenBank accession No. AB693161.1), and C. dubia (GenBank accession No. AB693163.1) were used to design Dsx-F and Dsx-R primers for a standard PCR to amplify the conserved region with the Primer Premier 5.0 software. A partial sequence of Dsx cDNA was amplified. The 3'-RACE and 5'-RACE primers were designed based on the partial sequence, as were the 3'-GSP, 5'-GSP, 3'-NEST, and 5'-NEST primers for nested PCR. 
The RT-F and RT-R primers for qRT-PCR were designed in the open reading frame (ORF) of the full-length cDNA sequence. In order to obtain more accurate test results, L8 ribosomal gene sequences were used as the reference gene for fluorescent quantitation, and this was amplified with primers L8-F and L8-R (Weng, 2011). Probe primers, pro-F, and pro-R were designed for the preparation of in situ hybridization probes. All primer sequences used in this study are found in Table 1.

\begin{tabular}{|c|c|c|}
\hline Primer & Sequence $\left(5^{\prime}-3^{\prime}\right)$ & Purpose \\
\hline Dsx-F & GCCCAGCAACAAGACAGAG & StandardPCR \\
\hline Dsx-R & GTGGTGGACAAATGACGGT & \\
\hline L8-F & CGTAGTCGGATGTCTGTCTTCG & L8 gene \\
\hline L8-R & GCAGATACAACAACGACGCA & \\
\hline 3'GSP & TCGCCATCCGACTTGGGAAGAAAC & RACE-PCR \\
\hline 5'GSP & GCCTAGCAGGAAGCATTCAAGAGCCAT & \\
\hline 3'NEST & TTTCGCTTCGTCTATTTCGCCATCCG & NestedPCR \\
\hline 5 'NEST & CTTCCCAAGTCGGATGGCGAAATAGA & \\
\hline RT-F & TCCGACTTGGGAAGAAACTC & qRT-PCR \\
\hline RT-R & CGGGAGCGTAATGAGATGG & \\
\hline pro-F & CCATCTCATTACGCTCCCG & Riboprobe \\
\hline pro-R & GGATTTCGCACTGGCATTA & \\
\hline
\end{tabular}

\section{Total RNA extraction and first-strand cDNA synthesis}

Total RNA was extracted from individuals stored at $-80^{\circ} \mathrm{C}$ using an RNA extraction kit (Axygen, USA) according to the manufacturer protocol. The first-strand cDNA for standard and qRT-PCR was synthesized using a reverse transcription kit (PrimeScript RT Master Mix Perfect Real-Time Kit, TaKaRa, Japan). The reaction program consisted of $37^{\circ} \mathrm{C}$ for 15 $\min$ and $85^{\circ} \mathrm{C}$ for $5 \mathrm{~s}$.

\section{Cloning of the cDNA fragment}

Using first-strand cDNA from the adult sexual females as a template, standard PCR was carried out. The reaction volume was $25 \mu \mathrm{L}$, and the optimized amplification procedure was as follows: $94^{\circ} \mathrm{C}$ denaturation for $5 \mathrm{~min} ; 94^{\circ} \mathrm{C}$ denaturation for $30 \mathrm{~s}, 55^{\circ} \mathrm{C}$ annealing for $30 \mathrm{~s}, 72^{\circ} \mathrm{C}$ extension for $1 \mathrm{~min}, 35$ cycles; $72^{\circ} \mathrm{C}$ extension for $10 \mathrm{~min}$; followed by preservation at $4^{\circ} \mathrm{C}$. PCR products were separated using $1.2 \%$ agarose gel electrophoresis and purified using a SanPrep column DNA gel extraction kit (Sangon, China). They were then sequenced by Majorbio, China. A BLAST search was used to compare the products against the NCBI database, and a partial cDNA sequence of $D s x$ was confirmed.

The 5'-RACE-Ready cDNA and 3'-RACE-Ready cDNA templates were prepared according to the SMARTer ${ }^{\mathrm{TM}}$ RACE cDNA Amplification Kit User Manual. The RACE-PCR amplification procedure was carried out using a touchdown PCR according to the manual. To increase the amplification efficiency and specificity, the RACE-PCR product was diluted 100fold as a nested PCR template. The annealing temperature of the nested PCR was $63^{\circ} \mathrm{C}$. PCR products were separated and purified as described above. PCR products were inserted into a pGEM-T vector (Promega, USA), and positive clones were identified using PCR, agarose gel electrophoresis, and sequencing. 


\section{Cloning of full-length cDNA and bioinformatics analysis}

The 5'-RACE-PCR and 3'-RACE-PCR sequencing results were compared to the NCBI database. The products were spliced with the intermediate sequence to obtain the full-length $D s x$ cDNA, which was named DapcaDsx2 according to NCBI database homology analysis.

The NCBI BLASTx tool was used to find and compare the homology of nucleic acid and protein sequences. The NCBI ORF finder was used for ORF analysis. SignalP was used for signal peptide identification. The isoelectric point (pI) and molecular weight (MW) of the protein were calculated using the EXPASY database, which was also used to predict the functional domains and active site residues.

The BLAST feature of the NCBI database was used to extract protein names, sequences, and amino acid numbers for subsequent phylogenetic analysis. Using the ClustalW software, we aligned the amino acid sequence encoded by DapcaDs $x 2$ with 20 other homologous $D s x$ sequences available in GenBank. The sequences used were from D. magna (GenBank accession No. BAJ78309.1), D. pulex (BAM33608.1), D. galeata (BAM33610.1), C. dubia (BAM33612.1), Moina macrocopa (BAM33613.1), Paralichthys olivaceus (ACD62474.1), Cynoglossus semilaevis (ACT83604.1), Tachysurus fulvidraco (ADM07317.1), Danio rerio (AAN61062.1), Rhinella marina (ACN54528.1), Pelodiscus sinensis (BAD99160.1), Chelonia mydas (EMP30456.1), Mauremys reevesii (BAG65667.1), Crocodylus palustris (ACD74919.1), Elaphe quadrivirgata (BAD99161.1), Protobothrops flavoviridis (BAF36482.1), Gallus gallus (AAF19034.1), Bos grunniens mutus (ELR53308.1), Bos taurus (ACN86339.1), and Homo sapiens (AAR89619.1). A phylogenetic tree was constructed with the MEGA4.0 software using the NJ method with a bootstrap value of 1000 .

\section{qRT-PCR analysis}

Primer concentration, template concentration, primer annealing temperatures, and other conditions were optimized. The efficiency of primers for qRT-PCR was determined using the Livak method (Livak and Schmittgen, 2001). The samples were run in biological triplicates. The reaction system contained: $12.5-\mu \mathrm{L}$ SYBR Premix Ex Taq II, $1-\mu \mathrm{L}$ template cDNA, $0.5 \mu \mathrm{L} 10 \mu \mathrm{M}$ primer $1,0.5 \mu \mathrm{L} 10 \mu \mathrm{M}$ primer 2 , and $\mathrm{ddH}_{2} \mathrm{O}$ to a total volume of $25 \mu \mathrm{L}$. The following reaction protocol was used: $95^{\circ} \mathrm{C}$ for $3 \mathrm{~min}, 95^{\circ} \mathrm{C}$ for $10 \mathrm{~s}, 58^{\circ} \mathrm{C}$ for $30 \mathrm{~s}$, for a total of 40 cycles. Expression was normalized against the ribosomal protein L8 gene (Weng, 2011), and a melting curve was constructed from the results. The experimental data are reported as means and standard deviation, and analyzed with the SPSS software, using one-way ANOVA, with a statistical significance of $\mathrm{P}<0.05$. Gene expression was calculated using the $2^{-\Delta \Delta \mathrm{Ct}}$ method (Lai et al., 2005).

\section{Preparation of riboprobes}

Using the pro-F and pro-R primers, the PCR amplified a 270-bp DNA fragment. The amplification conditions were: $94^{\circ} \mathrm{C}$ for $3 \mathrm{~min} ; 94^{\circ} \mathrm{C}$ for $30 \mathrm{~s}, 57^{\circ} \mathrm{C}$ for $30 \mathrm{~s}, 72^{\circ} \mathrm{C}$ for $1 \mathrm{~min}, 35$ cycles; $72^{\circ} \mathrm{C}$ for $10 \mathrm{~min}$. PCR products were detected by agarose gel electrophoresis. Products were purified, ligated into a pGEM-T vector (Promega, USA) using T4 DNA ligase (Promega, USA), and transformed into Escherichia coli strain DH5 $\alpha$, followed by blue-white screening, culturing, plasmid purification, and sequencing. According to the 
multiple cloning sites of the pGEM-T vector and digestion sites of DapcaDsx2, the restriction enzymes $S p h$ I and $\mathrm{NcoI}$ were used to linearize the vector and the gene, respectively. The digested fragments were gel-purified and used as the template for sense and antisense probes, respectively.

Choosing the promoters based on sequencing results, antisense and sense RNA probes were synthetized. The $20-\mu \mathrm{L}$ transcription system contained $4-\mu \mathrm{L} 5 \mathrm{X}$ transcription buffer, $2 \mu \mathrm{L} 100 \mathrm{mM}$ DTT, $0.5 \mu \mathrm{L} 40 \mathrm{U}$ RNase inhibitor, $8 \mu \mathrm{L}$ linear DNA $(<1 \mu \mathrm{g}), 2 \mu \mathrm{L} 10 \mathrm{X}$ DIG labeling mixture, $1 \mu \mathrm{L} 20 \mathrm{U} / \mu \mathrm{L}$ SP6 or T7RNA Polymerase and $2.5 \mu \mathrm{L}$ RNase-free $\mathrm{H}_{2} \mathrm{O}$. Reactions were mixed and incubated at $37^{\circ} \mathrm{C}$ for $2 \mathrm{~h}$. One-microliter DNase (RNase-free) was added to the system, and incubation was continued for a further $15 \mathrm{~min}$. After adding 1/9 volume of $5 \mathrm{M} \mathrm{LiCl}$ and two volumes of absolute ethanol, the incubation was continued at $-20^{\circ} \mathrm{C}$ overnight. Mixtures were centrifuged at $12,000 \mathrm{rpm}$ for $30 \mathrm{~min}$ at $4{ }^{\circ} \mathrm{C}$, and the supernatant was discarded. This was followed by washing with $75 \%$ ethanol, $60 \mu \mathrm{L} 75 \%$ ethanol was added, and the samples were centrifuged at 13,000 rpm for $5 \mathrm{~min}$. After thorough drying to remove residual ethanol, the RNA sediment was resuspended in $30 \mu \mathrm{L} \mathrm{DEPC}$ water with $1.5 \mu \mathrm{L} 20 \mathrm{U}$ RNA inhibitor added, and stored at $-80^{\circ} \mathrm{C}$.

\section{Whole-mount in situ hybridization}

The whole-mount in situ hybridization technique employed the methods used by Thisse et al. (Chavez et al., 1999; Mitchell and Crews, 2002; Thisse and Thisse, 2007), with changes based on the characteristics of $D$. carinata. Individual specimens were digested with proteinase $\mathrm{K}$ for about $15 \mathrm{~min}$. Through the exploration of gradient temperature, an optimum temperature of $65^{\circ} \mathrm{C}$ was established. Pre-hybridization at $65^{\circ} \mathrm{C}$ for $2.5 \mathrm{~h}$ was followed by the addition of $100 \mu \mathrm{L}$ of a 1:200 dilution of RNA probe in pre-hybridization solution, and incubation was continued at $65^{\circ} \mathrm{C}$ overnight. An antisense probe was used in the experimental group and a sense probe in the control group, to ensure specific hybridization signals. The following day, the samples were aspirated and gradient-washed. They were then blocked for about $2 \mathrm{~h}$ at room temperature using MAB blocking solution. Hybridization was detected using a 1:2,000 dilution of anti-DIG antibody (Roche, USA) at $4^{\circ} \mathrm{C}$ for $13 \mathrm{~h}$, followed by washing with MABT, TSM1, and TSM2, respectively. Samples were stained with NBT liquid dye (Roche, USA) at room temperature in the dark for $10 \mathrm{~min}$, and stored in 4\% PFA. Hybridization was visualized and recorded using a BX51 fluorescence microscope (Olympus, USA).

\section{RESULTS}

\section{Cloning full-length cDNA of the DapcaDsx2 gene}

Using cDNA from a sexual female as the template, a 444-bp fragment was acquired by PCR amplification using specific primers. BLASTx analysis revealed high similarity with the published $D s \times 2$ gene sequences of $D$. pulex, D. magna, and D. galeata. On this basis, 3'-RACE and 5'-RACE primers were designed for the amplification of fragments of 710 and $797 \mathrm{bp}$, respectively. Via sequence contrasting and splicing, we obtained a 1108-bp full-length cDNA of DapcaDsx2 (GenBank accession No. KF753236). 


\section{Characteristics of the DapcaDsx2 sequence}

The full-length cDNA comprised a 259-bp 3'-untranslated region (UTR), a 3'-polyA tail, but no 5'-UTR. It also contained an 849-bp ORF and four N-glycosylation sites. Residues 20-73 contained a highly conserved DM domain, and residues 196-234 contained an oligomerization domain, both of which could improve the specificity of DNA binding. The ORF encoded a protein composed of 282 amino acids with a calculated MW of 31,069.06 Da, and a theoretical pI of 9.14. Analysis of the amino acid composition encoded by DapcaDs 2 using the DNAMAN software showed that there were 33 alkali amino acids including 11 lysine (Lys), 22 arginine (Arg), and 23 acidic amino acids including 13 aspartic acid (Asp) and 10 glutamate (Glu). Regarding amino acid content, the proportion of hydrophobic amino acids $(27.3 \%)$ was lower than that of hydrophilic amino acids (37.2\%). (Figure 1)

A

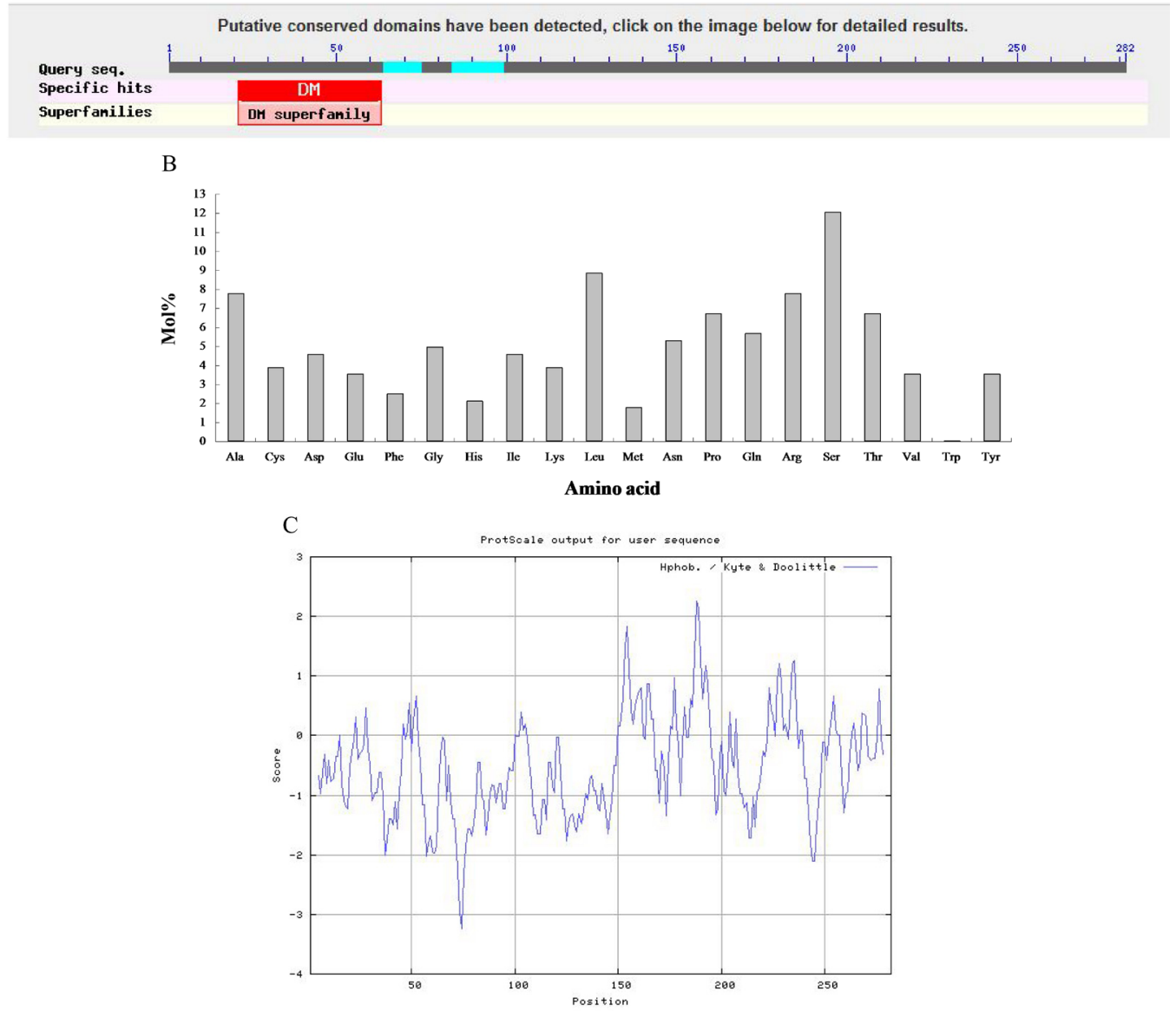

Figure 1. A. Distribution of DM domain. B. Composition of amino acid of DapcaDsx2. C. The graph indicated the hydrophilicity and hydrophobicity of the amino acid sequence (The abscissa axis represented the position of the amino acid sequence; the ordinate axis represented the value of hydrophilicity and hydrophobicity. The positive value indicated hydrophobicity, and the negative value indicated hydrophilicity). 


\section{Similarity of the DapcaDsx2 protein sequence with other Dsx ortholog proteins}

The results showed that the highest homology was shared with D. magna $(97.52 \%)$, followed by D. pulex (87.94\%), D. galeata $(85.11 \%)$, and C. dubia $(69.50 \%)$. Homology with the other 16 species ranged from 15 to $28 \%$ (Figure 2).

A phylogenetic tree of $21 D s x$ amino acid sequences was reconstructed using the NJ method with the MEGA 4.0 software. The results showed that the $D$. carinata Dsx2 gene was most closely related to the same gene in $D$. magna, forming one cluster. Both of these had a relatively close genetic relationship with the cladocerans $D$. pulex, D. galeata, C. dubia, and M. macrocopa, and formed one larger cluster. In terms of molecular evolutionary distance, the DapcaDs $x 2$ cDNA was closely related to crustacean sequences, and more distantly related to insects or other sequences (Figure 3).
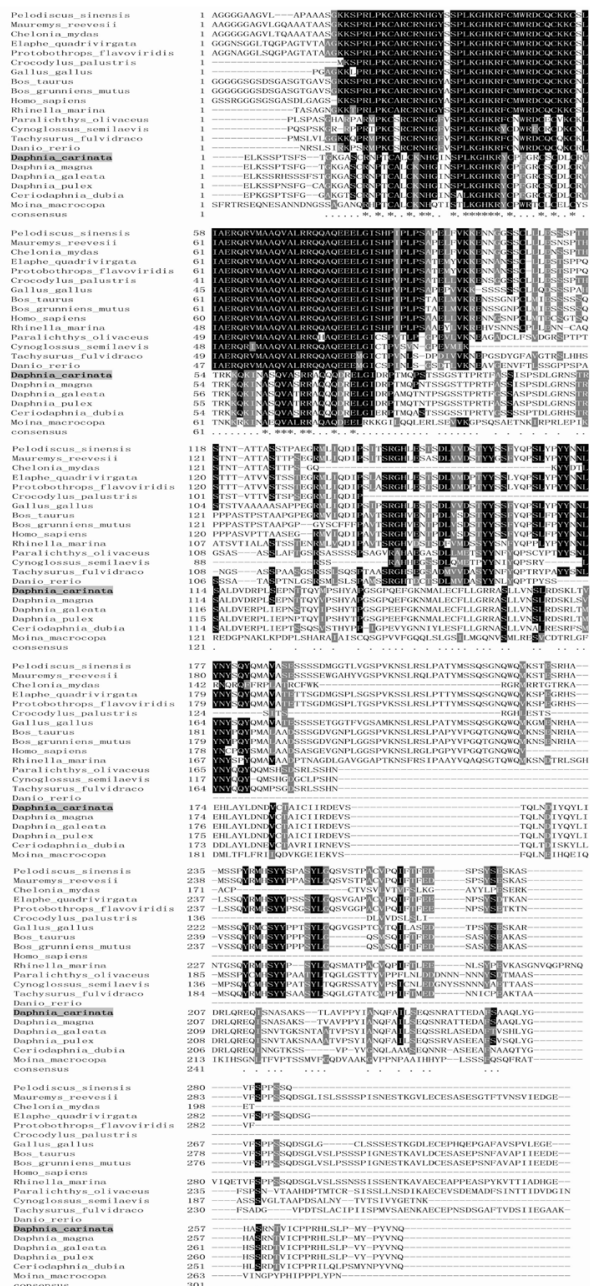

Figure 2. Multiple sequence alignment of DapcaDsx2 amino acid sequence with its closest homologs. Identical amino acids are highlighted in black, similar amino acids shown in gray. 


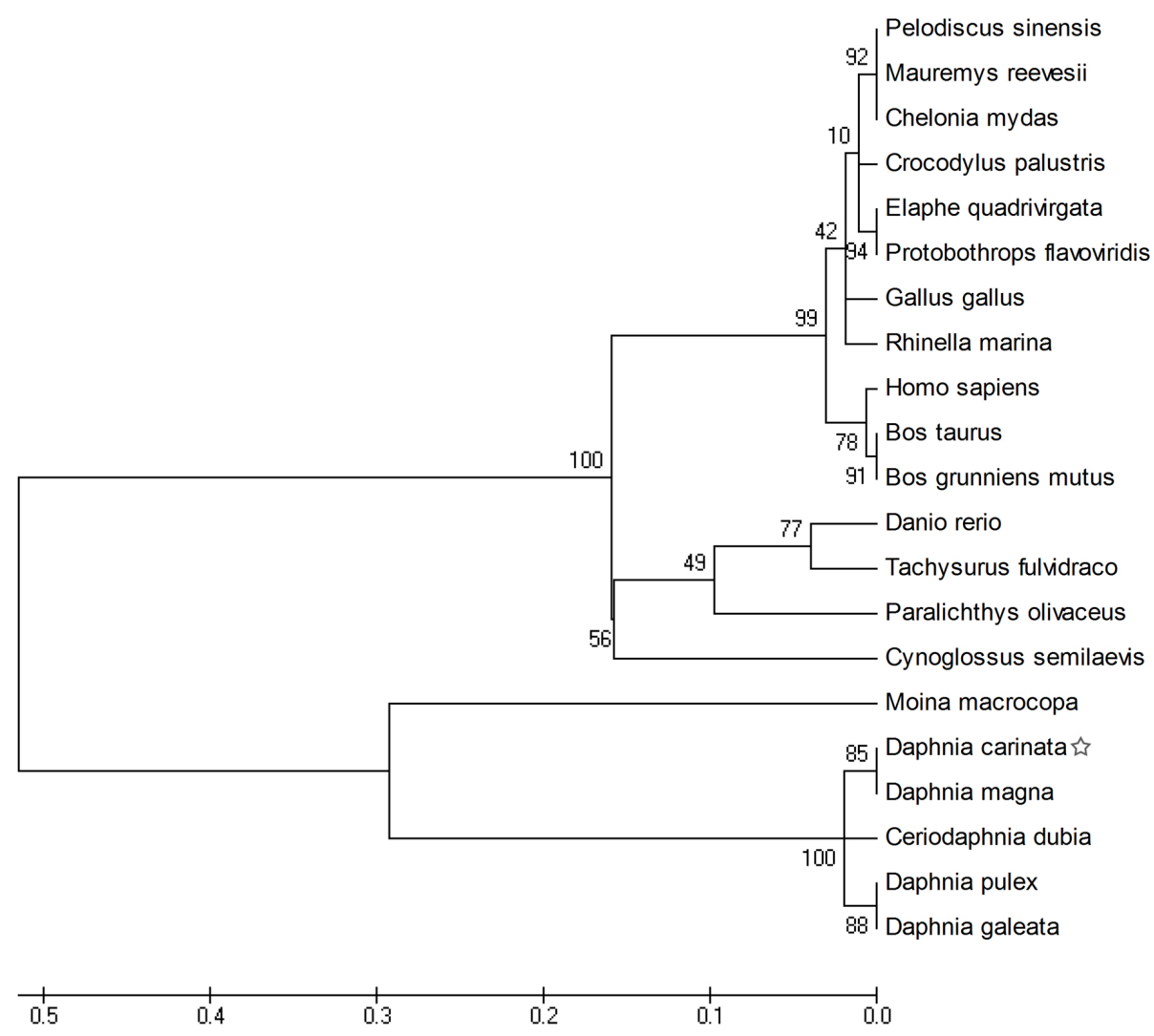

Figure 3. Neighbor-joining phylogenetic tree of DapcaDsx2 and Dsx sequences from other species.

\section{Analysis of DapcaDsx2 expression}

Using qRT-PCR, we analyzed the expression of DapcaDsx2 during five reproductive stages: juvenile females, parthenogenetic females (with summer eggs), prophase sexual females, sexual females, and resting eggs (Figure 4). DapcaDsx2 was most abundantly expressed in prophase sexual females and sexual females, followed by juvenile females and parthenogenetic females. The lowest expression was detected in the resting eggs. Expression levels of DapcaDs $x 2$ in asexual and sexual reproduction were significantly different $(\mathrm{P}<$ $0.05)$. Taken together, the results clearly show that DapcaDs 2 mRNA is expressed during the different reproductive stages.

DapcaDsx2 expression patterns were studied by whole-mount in situ hybridization using digoxin-labeled RNA probes. DapcaDsx2 was mainly expressed in the second antennae and several sites of the ventral carapace. In contrast, the expression level in sexual females was higher than that in parthenogenetic females. In addition, the sense probe detected no signal at the corresponding sites. These findings are consistent with the quantitative expression results, which indicated specific expression profiles of DapcaDsx2 mRNA in different reproductive stages (Figure 5). 


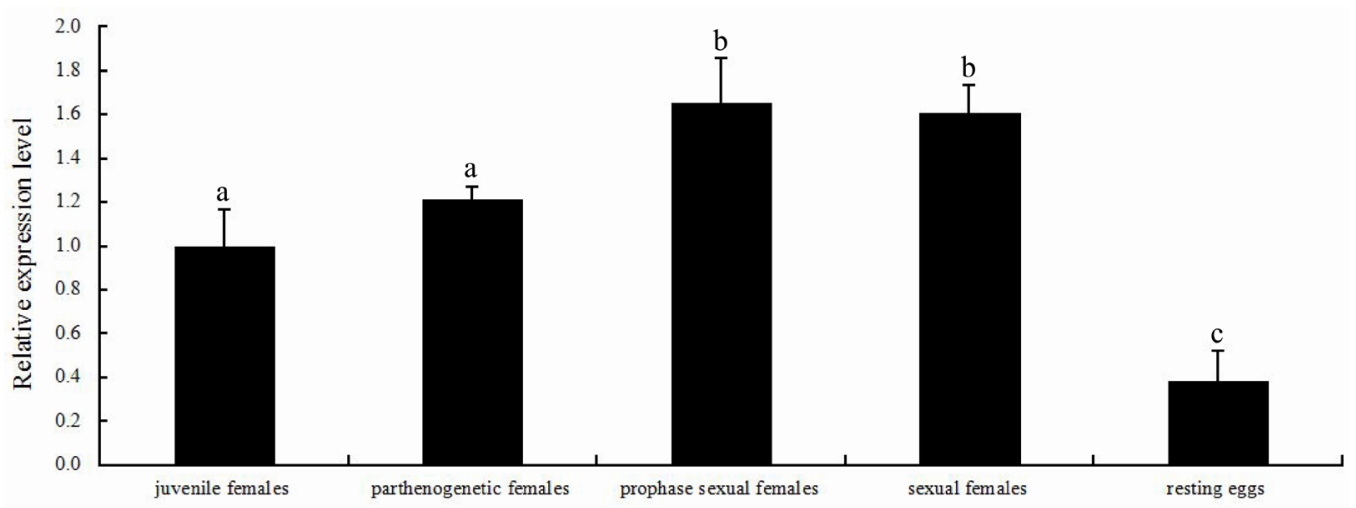

Figure 4. qRT-PCR of DapcaDsx 2 in individual organisms during five reproductive stages. Labeled bars $(\mathrm{a}, \mathrm{b}, \mathrm{c})$ indicate significant differences $(\mathrm{P}<0.05)$.
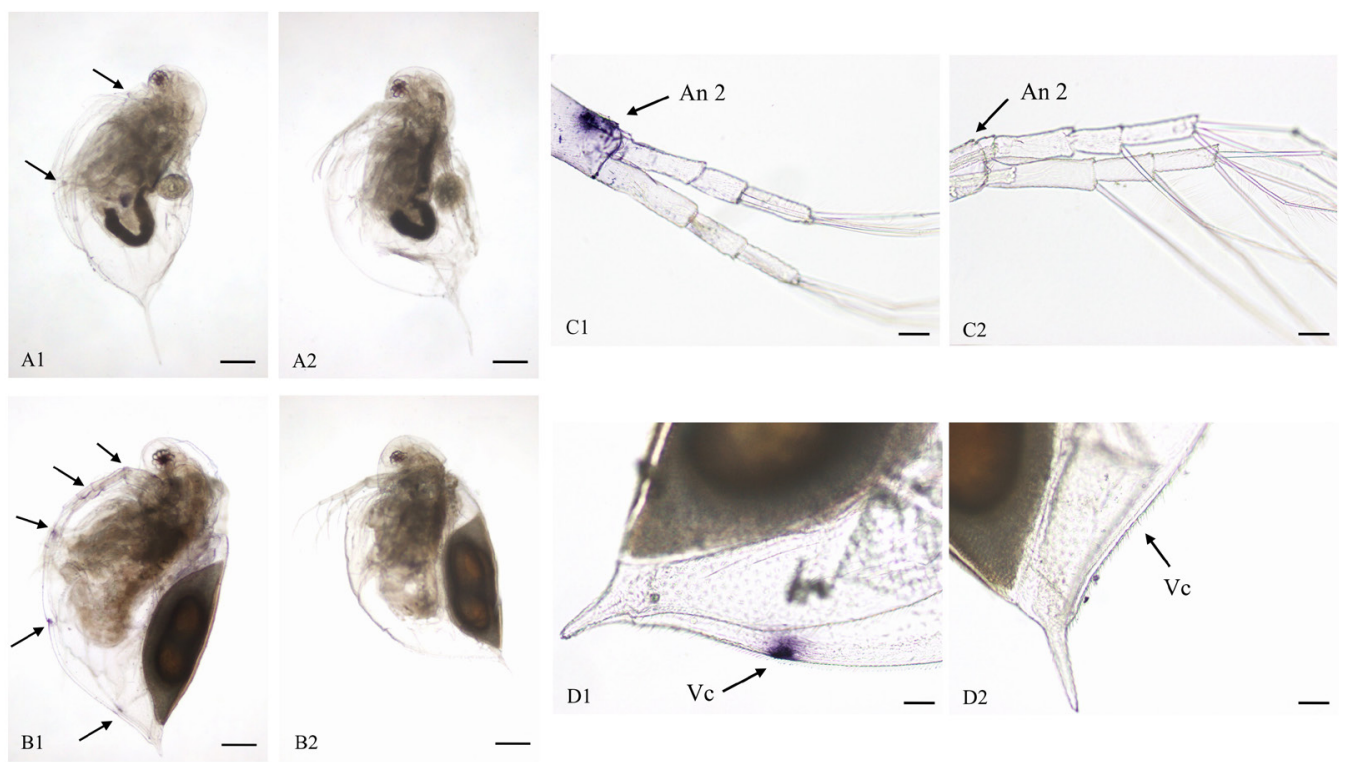

Figure 5. Whole-mount in situ hybridization in the body of Daphnia carinata (A1-D1: DIG-labeled DapcaDsx2 antisense probe; A2-D2: DIG-labeled DapcaDsx2 sense probe). The blue-violet area shows positive signals. A1. A2. Parthenogenetic Daphnia; B1. B2. sexual female Daphnia. Bar $=200 \mu \mathrm{m}$. C1. C2. D1. D2. Parts of the structure in sexual female Daphnia. An 2: second antenna; Vc: ventral carapace. Bar $=50 \mu \mathrm{m}$.

\section{DISCUSSION}

The Dsx gene is important and is known to be a sex-determining gene in insects. In the three-cascade gene pathway of sex-determination, it directly determines the sexual development of Drosophila. In females, the gene products of Dsx and Intersex synergistically promote the expression of female differentiation genes, resulting in female differentiation. In males, 
Sex-lethal $(S x l)$ is not activated, so that Transformer (Tra) is activated, resulting in a malespecific expression of Dsx, which leads to male differentiation (Sieved et al., 1997). Research has shown that expression of the Drosophila gene $S x l$ varies according to sex, a dimer being formed as a result of the female-specific regulation of $S x l$ generated by the TRA and TRA-2 binding protein encoded by Tra-2 (Lalli et al., 2003). The $D s x$ gene is also an important site of action of TRA and TRA-2 and is evolutionarily conserved, with homologs in Bactrocera tryoni, the Phoridae, and Bombyx mori Linnaeus (Sieved et al., 1997; Shearman and Frommer, 1998; Ohbayashi et al., 2001).

By comparing the sequences, the DapcaDsx2 amino acid sequence of $D$. carinata were found to have high similarity with those of D. magna, D. pulex, and D. galeata, but relatively low homology with species from other classes. The topology of the phylogenetic relationship for $D s x$ orthologs was in agreement with the taxonomic relationships. A phylogenetic analysis based on amino acid sequences revealed that DapcaDsx2 and other known Dsx proteins are conserved, especially among the cladocera. In the phylogenetic tree, $D$. carinata clustered with D. magna, D. pulex, D. galeata, C. dubia, and M. macrocopa within the same class. In a homology comparison with other species, $D s x$ amino acid sequences from different species possess a highly conserved region called the DM ( $D s x$ and Mab-3 related domain), which is derived from the Drosophila melanogaster Dsx gene and the Caenorhabditis elegans Mab-3 gene. This is an evolutionary highly conserved DNA binding domain, which can be found from vertebrates to invertebrates (Ottolenghi et al., 2002; Kazuyki et al., 2002). The DM domain contains a pair of cysteine residues in the N-terminal, and a pair of histidine residues in the C-terminal, which form a zinc finger structure (Raymond et al., 1998). The minimal DNA binding element is important in the Dsx protein, which is considered to determine gender (Raymond et al., 1999a,b).

qRT-PCR analysis of DapcaDsx2 gene expression revealed that the highest expression was found during sexual reproduction, followed by asexual reproduction. Dsx function has been co-opted to facilitate the evolution of environmentally cued intrasexual dimorphisms (Kijimoto et al., 2012), and it is known that Daphnia reproduction switches from parthenogenic to sexual females in response to environmental cues, so DapcaDsx2 expression levels differ between asexual and sexual reproduction (Liu et al., 2014). Taken together, these results clearly show that DapcaDsx 2 mRNA has a specific expression pattern during the different reproductive stages, and that DapcaDs 2 mRNA levels are significantly higher during sexual than asexual reproduction, indicating that it exhibits gender-specific expression, which would play an important role in regulating reproductive transformation in $D$. carinata.

In situ hybridization as a means to detect the RNA expression in cells and tissues has been widely described for D. rerio, Artemia, Drosophila and other species (Chavez et al., 1999; Mitchell and Crews, 2002; Thisse and Thisse, 2007), but studies on small cladocerans are much less common. In this study, we analyzed the spatial expression sites of DapcaDsx2 to ensure the integrity of $D$. carinata individuals by using digoxigenin-labeled RNA probes for the first time. Because the $D$. carinata body is encased in two slices of chitinous carapace, which might limit the efficiency of the RNA probe binding, proteinase $\mathrm{K}$ was used to permeabilize cells before hybridization. However, the concentration and treatment time of proteinase $\mathrm{K}$ are key to the success of the experiment. We found that the concentration of $10-\mu \mathrm{g} / \mathrm{mL}$ proteinase $\mathrm{K}$ was optimal, and that sexual organisms and parthenogenetic organisms were digested for 15 and $10 \mathrm{~min}$, respectively. Moreover, if the hybridization temperature is too low, nonspecific hybridization and background staining may take place, and if it is too high, incom- 
plete or no hybridization may result. Therefore, a temperature gradient was performed, and an optimum temperature of $65^{\circ} \mathrm{C}$ was established. To verify the specificity of the experiment, a parallel control was made. It showed no specific expression in sexual and parthenogenetic females by sense probes.

Following optimization, the in situ hybridization experiments showed that DapcaDsx2 was mainly expressed in the second antenna and parts of the ventral carapace, and higher expression levels were found in sexual than in parthenogenetic females. DapcaDs 2 mRNA was specifically expressed in different reproductive stages and might therefore play an important role in switching between the two reproduction strategies. The expression of DapcaDsx 2 was visible in the second antenna and carapace. The second antenna of $D$. carinata is a moving and sensory organ (Jiang and $\mathrm{Du}, 1979$ ). The carapace is equivalent to the carapace of other crustaceans, which cannot only be used to protect thoracic limbs, which lose the ability to move and become the tool of food intake, but can also be used to incubate their young (Shi, 2000). Some studies on the Dsx gene suggest that Dsx expression affects organ formation (Fujii and Shimada, 2007; Kato et al., 2011). Therefore, visible expression in such important organs could suggest a regulatory role of DapcaDsx 2 in the growth and development of $D$. carinata. However, the detailed molecular mechanisms and reasons for the expression of this gene in these organs need further study using RNA interference, ectopic expression, and immunohistochemical techniques.

\section{CONCLUSIONS}

This gene cloning and expression study showed that, DapcaDsx 2 is expressed in higher concentrations in sexually reproducing animals, and that it might be responsible for some sexual dimorphism. It is also likely that DapcaDsx 2 was switched activated because of other regulatory genes. This will be the subject of further research. In general, environmental sex determination is widespread in many fish and invertebrate species but is poorly understood. This study represents a step towards elucidating the molecular mechanisms involved.

\section{ACKNOWLEDGMENTS}

Research supported by grants from the National Natural Science Foundation of China (\#31172043) and the Natural Science Foundation of Zhejiang, China (\#LY12C19003). Parts of the study were conducted in the Instruments Sharing Platform of the School of Life Sciences, ECNU.

\section{REFERENCES}

Alekseev V and Lampert W (2001). Maternal control of resting egg production in Daphnia. Nature 414: 899-901.

Chavez M, Landry C, Loret S, Muller M, et al. (1999). APH-1, a POU homeobox gene expressed in the salt gland of the crustacean Artemia franciscana. Mech. Dev. 87: 207-212.

Crews D and Bull JJ (2009). Mode and tempo in environmental sex determination in vertebrates. Semin. Cell. Dev. Biol. 20: $251-255$

Fujii T and Shimada T (2007). Sex determination in the silkworm Bombyx mori: A female determinant on the W chromosome and the sex-determining gene cascade. Semin. Cell. Dev. Biol. 18: 379-388.

Jiang TZ and Du NS (1979). Fauna Sinica-freshwater cladocera. Science Press, Beijing.

Kato Y, Kobayashi K, Watanabe H and Iguchi T (2011). Environmental Sex Determination in the Branchiopod Crustacean Daphnia magna: Deep Conservation of a Doublesex Gene in the Sex-Determining Pathway. PLoS Genet. 7: 1-12. 
Kazuyki S, Minoru T and Mashisa N (2002). The Dmrtl expression in Sex-reversed gonad of amphibians. Gen. Comp. Endocr. 127: 232-242.

Kijimoto T, Moczek AP and Andrews J (2012). Diversification of doublesex function underlies morph-, sex-, and speciesspecific development of beetle horns. PNAS 109: 20526-20531.

Lai CY, Cheng W and Kuo CM (2005). Molecular cloning and characterisation of prophenoloxidase from haemocytes of the white shrimp, Litopenaeusv annamei. Fish. Shellfish. Immunol. 18: 417-430.

Lalli E, Ohe K, Latorre E, Bianchi ME, et al. (2003). Sexy splicing: regulatory interplays governing sex determination from Drosophila to mammals. J. Cell. Sci. 116: 441-445.

Li XY and Zhang JZ (2006). Effects of Toxic Alga Microcystis aeruginosa on Growth and Reproduction of Water Fleas Daphnia magna. Fish. Sci. 25: 632- 634.

Liu AJ, Zhang MQ, Kong L, Wu DL, et al. (2014). Cloning and expression profiling of a cuticular protein gene in Daphnia carinata. Dev. Genes. Evol. 224: 129-135.

Livak KJ and Schmittgen TD (2001). Analysis of relative gene expression data using real-time quantitative PCR and the $2^{-\Delta \Delta \mathrm{Ct}}$ method. Methods 25: 402-408.

Marshall-Graves JA (2008). Weird animal genomes and the evolution of vertebrate sex and sex chromosomes. Annu. Rev. Genet. 42: 565-586.

Martinez JF, Villasenor R, Rios G and Espinosa F (1994). Effect of food type and concentration on the survival, longevity and reproduction of Daphnia magna. Hydrobiologia 287: 207-214.

Matsuda M, Nagahama Y, Shinomiya A, Sato T, et al. (2002). DMY is a Y-specific DM-domain gene required for male development in the medaka fish. Nature 417: 559-563.

Mitchell B and Crews ST (2002). Expression of the Artemia trachealess gene in the salt gland and epipod. Evol. Dev. 4:344-353.

Ohbayashi F, Suzuki MG, Mita K, Okano K, et al. (2001). A homologue of the Drosophila doublesex gene is transcribed into sex-specific mRNA isoforms in the silkworm, Bombyx mori. Comp. Biochem. Physiol. B Biochem. Mol. Biol. 128: $145-158$.

Ottolenghi C, Fellous M, Barbieri M and Mc-Elreavey K (2002). Novel paralogy relations among human chromosomes support a link between the phylogeny of doublesex-related genes and the evolution of sex determination. Genomics 79: 333-343.

Pedrozo CDS and Bohrer MBC (2003). Effect of culture medium and food quantity on the growth, fecundity and longevity of the cladoceran Daphnia similis Claus. Acta. Limnol. Bras. 15: 43-49.

Rao XZ, Xu YQ, Chen YS and You YB (2002). Moina irrasa Brehm-A new kind of Daphnia toxicity test material. Biotechnology 10: 17-19.

Raymond CS, Shamu CE, Shen MM, Seifert KJ, et al. (1998). Evidence for evolutionary conservation of sex determining genes. Nature 391: 691-695.

Raymond CS, Kettlewell JR, Hirsch B, Bardwell VJ, et al. (1999a). Expression of DMRT1 in the genital ridge of mouse and chicken embryos suggests a role in vertebrate sexual development. Dev. Biol. 215: 208-220.

Raymond CS, Parker ED, Kettlewell JR, Brown LG, et al. (1999b). A region of human chromosome 9p required for testis development contains two genes related to known sexual regulators. Hum. Mol. Genet. 8: 989-996.

Shearman DC and Frommer M (1998). The Bactrocera tryoni homologue of the Drosophila melanogaster sex determination gene doublesex. Insect. Mol. Biol. 7: 355-366.

Shi XB (2000). Daphnia carinata and its cultivation. Bull. Biol. 35:14-17.

Sieved V, Kuhn S and Traut W (1997). Expression of the sex determining cascade genes sex-lethal and doublesex in the phorid fly Megaselia scalaris. Genome 40: 211-214.

Thisse C and Thisse B (2007). High-resolution in situ hybridization to whole-mount zebrafish embryos. Nat. Protoc. 3: 59-69.

Toyota K, Kato Y, Sato M, Sugiura N, et al. (2013). Molecular cloning of doublesex genes of four cladocera (water flea) species. BMC Genomics 14: 239.

Valenzuda N, Leclere A and Shikano T (2006). Comparative gene expression of steroidogenic factor 1 in Chrysemys picta and Apalone mutica turtles with temperature-dependent and genotypic sex determination. Evol. Dev. 8: 424-432.

Wallace H and Wallace BM (2000). Sex reversal of the new Triturus cristatus reared at extreme temperatures. Int. J. Dev. Biol. 44: 807-810.

Weng XL (2011). Studies on reproduction and development and cloning, characterization, expression of the cuticle protein gene in Daphnia carinata. Master's thesis East China Normal University.

Yoshimoto S, Okada E, Umemoto H, Tamura K, et al. (2008). A W-linked DM-domain gene, DM-W, participates in primary ovary development in Xenopus laevis. Proc. Nat. Acad. Sci. U.S.A. 105: 2469-2474.

Zhang MF (2005). Studies on reproduction and development in Daphnia (Ctenodaphnia) carinata. Doctoral thesis. East China Normal University. 